\title{
Examination of Effective Buccal Absorption of Salmon Calcitonin Using Cell-Penetrating Peptide-Conjugated Liposomal Drug Delivery
}

\section{System}

\author{
Taekwang Keum ${ }^{1,2, *}$, Gyubin Noh ${ }^{1,2, *}$, Jo-Eun Seo', Santosh Bashyal',2, Dong Hwan Sohn (D)', \\ Sangkil Lee ${ }^{1,2}$ \\ 'College of Pharmacy, Keimyung University, Daegu, Republic of Korea; ${ }^{2}$ Center for Forensic Pharmaceutical Science, Daegu, Republic of Korea \\ *These authors contributed equally to this work \\ Correspondence: Sangkil Lee, College of Pharmacy, Keimyung University, 1095 Dalgubeol-daero, Dalseo-gu, Daegu, 4260I, Republic of Korea, \\ Tel +82-53-580-6655, Fax +82-53-580-5164, Email skdavid@kmu.ac.kr
}

\begin{abstract}
Introduction: The buccal route has been considered an attractive alternative delivery route for injectable formulations. Cellpenetrating peptides (CPPs) are gaining increased attention for their cellular uptake and tissue permeation effects. This study was aimed to evaluate the in vitro and ex vivo permeation-enhancing effect of penetratin-conjugated liposomes for salmon calcitonin (sCT) in TR146 human buccal cells and porcine buccal tissues.

Methods: Penetratin was conjugated to phospholipids through a maleimide-thiol reaction. Liposomes were prepared and sCT was encapsulated using a thin-film hydration method. Physical properties such as particle size, zeta potential, encapsulation efficiency, and morphological images via transmission electron microscopy were obtained. Cellular uptake studies were conducted using flow cytometry (FACS) and confocal laser scanning microscopy (CLSM). A cell permeation study was performed using a Transwell ${ }^{\mathbb{B}}$ assay, and permeation through porcine buccal tissue was evaluated. The amount of SCT permeated was quantified using an ELISA kit and was optically observed using CLSM.

Results: The particle size of penetratin-conjugated liposomes was approximately $123.0 \mathrm{~nm}$, their zeta potential was $+29.6 \mathrm{mV}$, and their calcitonin encapsulation efficiency was $18.0 \%$. In the cellular uptake study using FACS and CLSM, stronger fluorescence was observed in penetratin-conjugated liposomes compared with the solution containing free sCT and control liposomes. Likewise, the amount of SCT permeated from penetratin-conjugated liposomes was higher than that from the free sCT solution and control liposomes by 5.8-fold across TR146 cells and 91.5-fold across porcine buccal tissues.
\end{abstract}

Conclusion: Penetratin-conjugated liposomes are considered a good drug delivery strategy for sCT via the buccal route.

Keywords: buccal drug delivery, peptide delivery, penetratin, liposomes, TR146 cells, porcine buccal tissues

\section{Introduction}

Calcitonin is a hormone consisting of 32 amino acids long secreted from the $\mathrm{C}$ cells of the mammalian thyroid. This hormone was discovered by Copp et al, where they found that it lowers blood calcium levels. ${ }^{1}$ Calcitonin is an endogenous physiological hormone that inhibits bone resorption and is used as a treatment for diseases related to bone resorption, such as postmenopausal osteoporosis, to reduce the adherence of osteoclasts and osteoclast formation. ${ }^{2,3}$ Other types of synthetic or recombinant calcitonin, such as human calcitonin, porcine calcitonin, and salmon calcitonin (sCT), have been used for medical purposes. Among them, sCT has been the most widely used, as it has a 40-50-fold higher efficacy than human calcitonin. ${ }^{4-6}$ 
Oral administration is a drug delivery route preferred in clinical practice and is associated with high patient compliance. ${ }^{7}$ However, biopharmaceuticals such as sCT have a high molecular weight and hydrophilicity. There are many difficulties facing drug delivery through the gastrointestinal (GI) tract. Protease action, hydrolysis, and hepatic first-pass effects occur in the GI tract. To overcome such limitations, intravenous injection is usually used. ${ }^{8}$ As biopharmaceuticals are substances with short half-life, they are administered frequently. Hence, patient compliance is low due to needle phobia, pain caused by intravenous injection, and difficulties in self-administration. ${ }^{7,9,10}$ Various mucous membranes, such as the nasal, rectal, vaginal, ocular, pulmonary, and buccal membranes, are considered alternative drug delivery methods for the delivery of biopharmaceutical substances. ${ }^{10}$

In contrast to oral administration, alternative drug delivery methods offer a milder environment for the absorption of biopharmaceuticals. Compared to other non-oral administration routes, the buccal route may lead to high patient compliance due to its easy administration and lower incidence of irritation. ${ }^{8,9}$ The buccal route is abundant in blood vessels, and the administered drug can directly enter the jugular veins via the blood vessels, allowing its absorption into the systematic circulation. In emergencies, formulations can also be immediately removed, ${ }^{10}$ repetitive administration is possible, and the buccal tissues can quickly recover. ${ }^{11}$

Liposomes are artificial lipid bilayer vesicles made from non-toxic lipids and are biocompatible ${ }^{12}$ with their characteristics depending on their lipid composition. ${ }^{13}$ Liposomes can increase the permeation of incorporated drugs and simultaneously encapsulate both hydrophilic and hydrophobic drugs. ${ }^{14,15} \mathrm{It}$ is possible to change their vesicle size, modify their surface properties (to be positively or negatively charged), and decorate them with various ligands such as antibodies, polymers, and cell-penetrating peptides. ${ }^{13,16,17}$ Various studies on buccal drug delivery using liposomes are currently underway. Liposomal buccal mucoadhesive films containing vitamin B6 were prepared to have improved stability, ${ }^{16}$ deformable liposomes containing sodium deoxycholate have been prepared to increase the bioavailability of insulin $^{18}$ and the bioavailability of silymarin and rifampicin was increased through liposome encapsulation. ${ }^{19,20}$ Elastic liposomes containing bile salt increased the permeation of insulin in TR 146 cells and porcine buccal tissues. ${ }^{21,22}$

Cell-penetrating peptides (CPPs), which are short (less than 30 amino acids long) cationic, amphipathic peptides, have attracted attention in the past few decades as an effective cellular uptake tool. ${ }^{23,24} \mathrm{CPPs}$ can deliver various cargo molecules (DNA, siRNAs, peptides, proteins, oligonucleotides, and nanoparticles) in vitro and in vivo with high efficiency and low toxicity. ${ }^{25,26}$ By using CPPs, surface modification and covalent and noncovalent bonding of cargo molecules have been done to deliver biopharmaceuticals. ${ }^{27}$ CPPs have also been considered a strategic choice to overcome the limitations of delivering high-molecular-weight and hydrophilic biopharmaceuticals through cell membranes and tissues. Among non-invasive routes, the delivery of biopharmaceuticals via the nasal, pulmonary, transdermal, and ocular pathways using CPPs has been actively studied. However, the delivery of biopharmaceuticals via the buccal route has been less studied than other delivery routes. A recent study reported that LMWP-conjugated insulin and a physical mixture of LMWP with insulin were effectively delivered via the buccal pathway. ${ }^{28}$ A physical mixture of Penetratin and sCT was evaluated in the buccal pathway. Penetratin increased the permeation of sCT by acting as an effective permeation enhancer. ${ }^{29}$

In this study, we designed penetratin-conjugated liposomes to enhance sCT penetration via the buccal route. The physical properties of typical liposomes and penetratin-conjugated liposomes were measured, imaging studies were performed using Alexa 647-sCT-incorporated liposomes via flow cytometry (FACS) and confocal laser scanning microscopy (CLSM), and the amount of sCT permeated in TR146 cells and buccal tissues were measured using an sCT ELISA kit.

\section{Materials and Methods}

\section{Materials}

Salmon calcitonin (sCT) was purchased from Bachem AG (Bubendorf, Switzerland). The peptide CRQIKIWFQNRRMKWKK (Cys-penetratin) was synthesized and purchased from Peptron Co., Ltd. (Daejeon, Republic of Korea). The lipid 1,2-dioleoyl-sn-glycero-3-phosphoethanolamine-N-[4-(p-maleimidophenyl) butyramide] (MPB-PE) was purchased from Avanti Polar Lipids (Alabaster, AL). L- $\alpha$-lecithin (97.7\% phosphatidylcholine) was 
purchased from Merck Millipore (Billerica, MA, USA). Tween $80^{\circledR}$ was purchased from Duksan (Ansan, Republic of Korea). An sCT ELISA kit was purchased from Phoenix Pharmaceuticals (Burlingame, CA, USA). A Ham-F-12 Nutrient mixture (Ham's F-12) was purchased from Welgene (Gyeongsan-si, Republic of Korea). A CellTiter $96^{\circledR}$ Aqueous One Solution Cell Proliferation Assay kit (MTS) was purchased from Promega (Madison, WI, USA). Alexa Fluor 647 NHS Ester, SnakeSkin ${ }^{\mathrm{TM}}$ dialysis tubing (3.5 K MWCO), fetal bovine serum (FBS), 0.25\% trypsin-EDTA, and penicillin/ streptomycin were purchased from Thermo Fisher Scientific (Waltham, MA, USA). All other chemicals and solvents were of reagent grade.

\section{Preparation of Liposomes \\ Preparation of Control Liposomes}

Control liposomes were prepared using the film hydration method. ${ }^{13}$ Briefly, L- $\alpha$-Lecithin and Tween $80^{\circledR}$ were blended at a molar ratio of 9:1 and dissolved in chloroform. An organic solution containing lipids was evaporated using a rotary evaporator. After purging with nitrogen to remove the residual organic solvent, the thin film was dried overnight. The dried thin film was rehydrated using $40 \mu \mathrm{g} / \mathrm{mL}$ of a sCT PBS solution (pH 7.4) at a final lipid concentration of $10 \mathrm{mg} / \mathrm{mL}$. Liposomes were extruded using an Avanti Mini-Extruder with a $0.2-\mu \mathrm{m}$ filter.

\section{Conjugation of Penetratin and MPB-PE}

Penetratin-conjugated liposomes were prepared using MPB-PE and Cys-penetratin. For the specific binding of penetratin and liposomes, Cys-penetratin with Cysteine added to the N-terminus of Penetratin and MPB-PE containing a Maleimide group were used. MPB-PE was conjugated with Cys-penetratin via a maleimide-thiol reaction. ${ }^{30,31}$ To produce MPB-PE liposomes, L- $\alpha$-Lecithin, Tween $80^{\circledR}$, and MPB-PE were mixed at a fixed molar ratio of 89:10:1 (MPB-PE was fixed at $121 \mu \mathrm{M})$ and dissolved in chloroform in a round flask. MPB-PE liposomes were prepared according to the method described in Section 2.2.1. For the thiol-maleimide reaction, Cys-penetratin was added to the MPB-PE liposomes, the $\mathrm{pH}$ was adjusted to 7.4 , and then reacted for $12 \mathrm{~h}$ at $4{ }^{\circ} \mathrm{C}$. The chemical structure and a schematic diagram of the maleimidethiol reaction are shown in Figure 1.

\section{Characterization of Penetratin-Conjugated Liposomes \\ Size and Zeta Potential of the Liposomes}

The size and zeta potential of the liposomal formulations were measured using ZetaPlus (Brookhaven Instruments Corp., Holtsville, NY, USA) after a 100-fold dilution with distilled water. The measurements were repeated three times.

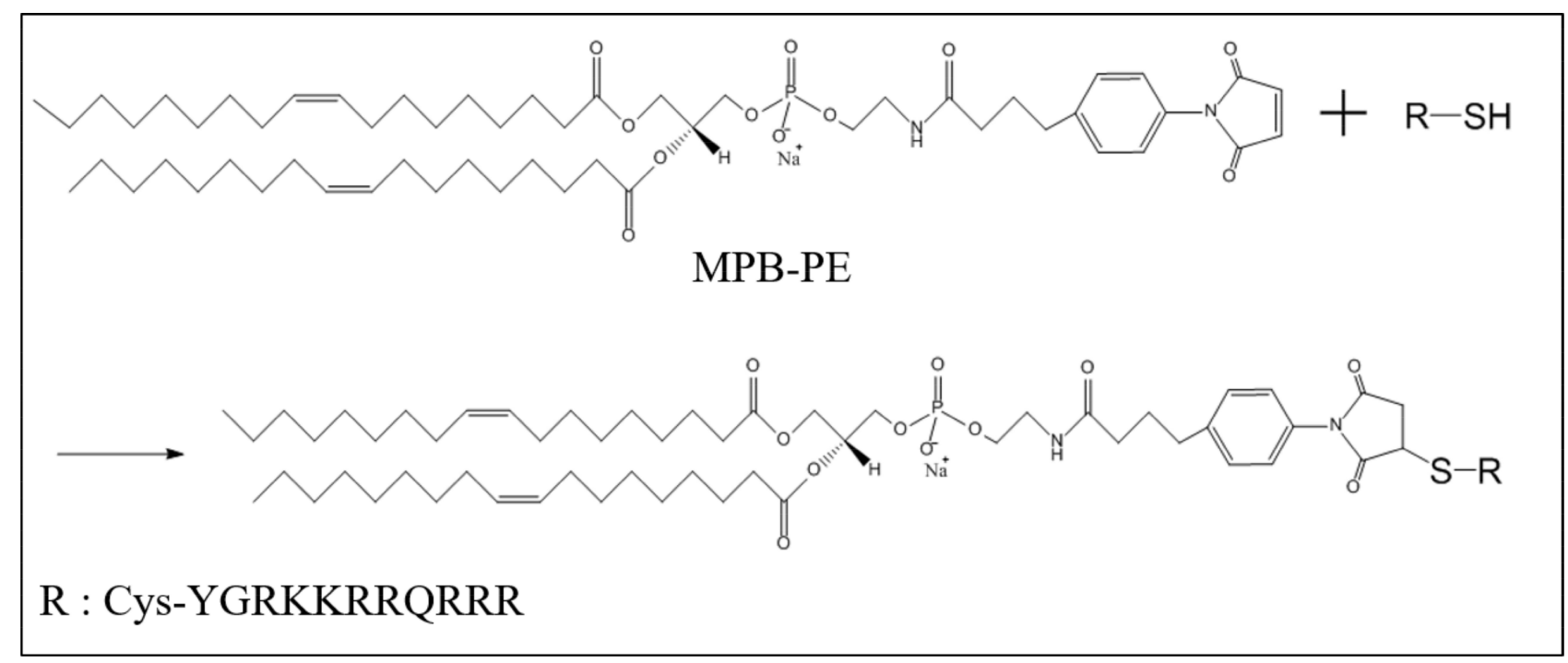

Figure I Schematic diagram of the chemical structure and the reaction of Cys-penetratin and MPB-PE used to prepare penetratin-conjugated liposomes. 


\section{Encapsulation Efficiency}

The encapsulation efficiency of sCT in the liposomes was measured using a Beckman Coulter Optima LE-80K ultracentrifuge (Beckman Coulter Corp., Pasadena, CA). Liposomes were centrifuged at $100,000 \times \mathrm{g}$ and $4{ }^{\circ} \mathrm{C}$ for $1 \mathrm{~h}$. The supernatant was collected and analyzed using an ELISA kit. The encapsulation efficiency was calculated using the following formula:

$$
\text { Encapsulation efficiency }(\%)=\frac{T-C}{T} \times 100
$$

where $\mathrm{T}$ is total initial amount of $\mathrm{sCT}$ added and $\mathrm{C}$ is the amount of $\mathrm{SCT}$ in the supernatant.

\section{Transmission Electron Microscopy}

The morphology of the liposomes was determined via TEM (H-7600, HITACHI Ltd., Tokyo, Japan). Liposomes were negatively stained using $2 \%$ phosphotungstic acid and spread on a carbon-coated copper grid. The carbon-coated copper grid was then dried, and the samples were observed at $10,000 \times$ magnification.

\section{TRI46 Cell Culture}

The TR146 cell line (ECACC 10032305) was purchased from Public Health England (London, UK). TR146 cells were incubated in Ham's F-12 medium supplemented with 10\% FBS, 2 mM glutamine, penicillin $(10,000$ units $/ \mathrm{mL})$, and streptomycin $(10,000 \mu \mathrm{g} / \mathrm{mL})$, and incubated at $37{ }^{\circ} \mathrm{C}$ in $5 \% \mathrm{CO}_{2}$. The medium was replaced every $2-3$ days. When the cultures reached $70-80 \%$ confluency, the cells were harvested for subculture using a $0.25 \%$ trypsin-EDTA solution.

\section{Cytotoxicity Assay}

Cell viability was determined by comparing with control (no treated group) using MTS assay. Briefly, $1.0 \times 10^{4}$ TR 146 cells were seeded in a 96-well plate and incubated for $24 \mathrm{~h}$. After $24 \mathrm{~h}$, the media was removed and $100 \mu \mathrm{L}$ of a liposome solution at different concentrations $(10,5,2.5$ and $1.25 \mathrm{mg} / \mathrm{mL})$ were added and the cells were incubated for another $24 \mathrm{~h}$. Then, the samples were removed and $100 \mu \mathrm{L}$ of fresh culture media and $20 \mu \mathrm{L}$ of CellTiter $96^{\circledR}$ solution were added and incubated with the cells for $2 \mathrm{~h}$. The optical density was then measured at $490 \mathrm{~nm}$ using a microplate reader. Cell viability was calculated using the following formula:

$$
\text { Cell viability }(\%)=\frac{O D_{490(\text { sample })}-O D_{490(\text { control })}}{O D_{490(\text { sample })}-O D_{490(\text { control })}} \times 100
$$

where $\mathrm{OD}_{490}$ is the optical density at $490 \mathrm{~nm}$.

\section{In vitro Cellular Uptake Study}

Preparation of Liposomes for the Cell Uptake Study

Alexa $647-\mathrm{sCT}$ was synthesized for cellular uptake studies. To prepare this, $\mathrm{sCT}$ was dissolved in $0.1 \mathrm{M}$ sodium bicarbonate buffer. Alexa 647 was dissolved in DMSO and allowed to react for $2 \mathrm{~h}$ with the sCT solution at room temperature. After $2 \mathrm{~h}$, a large quantity of ammonium chloride was added to terminate the reaction, and the resulting solution was purified via dialysis. The synthesized Alexa 647-sCT was encapsulated into the control liposomes and penetratin-conjugated liposomes for subsequent imaging studies.

\section{Flow Cytometry}

A cellular uptake study was conducted using TR146 cells via flow cytometry. TR146 cells were seeded in a 6-well culture plate at a density of $5.0 \times 10^{5}$ cells per well and incubated for $24 \mathrm{~h}$ at $37{ }^{\circ} \mathrm{C}$ in an atmosphere of $5 \% \mathrm{CO}_{2}$. Liposomes encapsulating Alexa 647-sCT were incubated for $2 \mathrm{~h}$. After incubation, the cells were washed three times with DPBS, and $0.25 \%$ trypsin-EDTA was added for $10 \mathrm{~min}$ to harvest the cells. After obtaining the cells, they were collected in FACS buffer and analyzed immediately using FACS. 


\section{Confocal Laser Scanning Microscopy}

CLSM was used to visualize the cellular uptake of the liposomes. Approximately 5.0 $\times 10^{5}$ TR146 cells were seeded and incubated for $24 \mathrm{~h}$ at $37{ }^{\circ} \mathrm{C}$ in an atmosphere of $5 \% \mathrm{CO}_{2}$. Alexa 647 -sCT-loaded liposomes were then added to the cells and were incubated for $24 \mathrm{~h}$. After incubation, the cells were washed three times with DPBS and fixed for $10 \mathrm{~min}$ in $4 \%$ formalin. DAPI (4',6'-diamidino-2-phenylindole) staining was conducted and the cells were immediately observed using CLSM.

\section{In vitro Cell Permeation Study}

To observe the cell permeation efficacy of the liposomes, a cell permeation study using Transwell ${ }^{\circledR}$ inserts was conducted. TR 146 cells $\left(5 \times 10^{4}\right)$ were seeded in 12-well Transwell ${ }^{\circledR}$ inserts, and the media was changed every other day for 28 days. Culturing TR146 cells in Transwell ${ }^{\circledR}$ inserts for 3-4 weeks formed 4 to 7 layers of flattened cells and showed a constant TEER value. ${ }^{32}$ Aliquot of liposomes solution $(500 \mu \mathrm{L})$ containing $40 \mu \mathrm{g} / \mathrm{mL}$ sCT were added to the apical chamber of the Transwell ${ }^{\circledR}$ insert for cell permeation study. After $0.5,1,2,4$, and $8 \mathrm{~h}, 500 \mu \mathrm{L}$ sample was obtained from the basolateral chamber and the same amount of HBSS-HEPES buffer ( $\mathrm{pH} 7.4$ ) was added. The amount of sCT that permeated the TR146 cell layers was quantified using an sCT ELISA kit.

\section{Pretreatment of Porcine Buccal Tissues}

Buccal pretreatment was performed according to the experimental method of Oh et al. ${ }^{33}$ After sacrificing pigs at a slaughterhouse, fresh porcine buccal tissues were immediately obtained, and the fatty and connective tissue were removed. The collected tissues were placed in a PBS solution (pH 7.4) at $60^{\circ} \mathrm{C}$ for $1 \mathrm{~min}$ to obtain the buccal epithelium. The prepared epithelial tissues were then used for the in vitro tissue permeation experiments.

\section{Ex vivo Buccal Tissue Permeation Study}

The permeation efficacy of the penetratin-conjugated liposomes was determined using porcine buccal tissues. The amount of sCT permeated was confirmed using a Franz diffusion cell. The area of the donor part was maintained at $2.0 \mathrm{~cm}^{2}$ and the volume of media in the receptor was $12.5 \mathrm{~mL}$. The receptor was filled with PBS (pH 7.4) and was equilibrated for the next 30 min after mounting the buccal tissues. After $1 \mathrm{~mL}$ of each liposome solution was added to the donor, samples $(0.5 \mathrm{~mL})$ were obtained from the receptor after $1,2,4$, and $8 \mathrm{~h}$. The permeated $\mathrm{sCT}$ was analyzed using an sCT ELISA kit.

\section{Permeation Parameters}

The flux $\left(J_{S}\right)$ was calculated using the following formula:

$$
J_{s}=\frac{Q_{r}}{A \cdot t}\left(n g \cdot \mathrm{cm}^{-2} \cdot h^{-1}\right)
$$

where $Q_{r}$ is the amount of sCT permeated (ng), A is the permeation area $\left(\mathrm{cm}^{2}\right)$, and $\mathrm{t}$ is the permeation time of $\mathrm{sCT}(\mathrm{h})$.

Further, $K_{p}$ was calculated using the following formula:

Table I Physical Characteristics of the Liposome Formulations

\begin{tabular}{|l|c|c|}
\hline & Control Liposomes & Penetratin-Conjugated Liposomes \\
\hline Size $(\mathrm{nm})$ & $118.1 \pm 12.6$ & $123.0 \pm 13.5$ \\
\hline Zeta potential $(\mathrm{mV})$ & $-15.7 \pm 3.0$ & $29.6 \pm 3.6$ \\
\hline Poly dispersity index (PDI) & $0.155 \pm 0.024$ & $0.151 \pm 0.034$ \\
\hline Encapsulation efficiency (\%) & $27.1 \pm 0.91$ & $18.0 \pm 1.52$ \\
\hline
\end{tabular}

Note: Data are expressed as mean $\pm S D(n=3)$. 

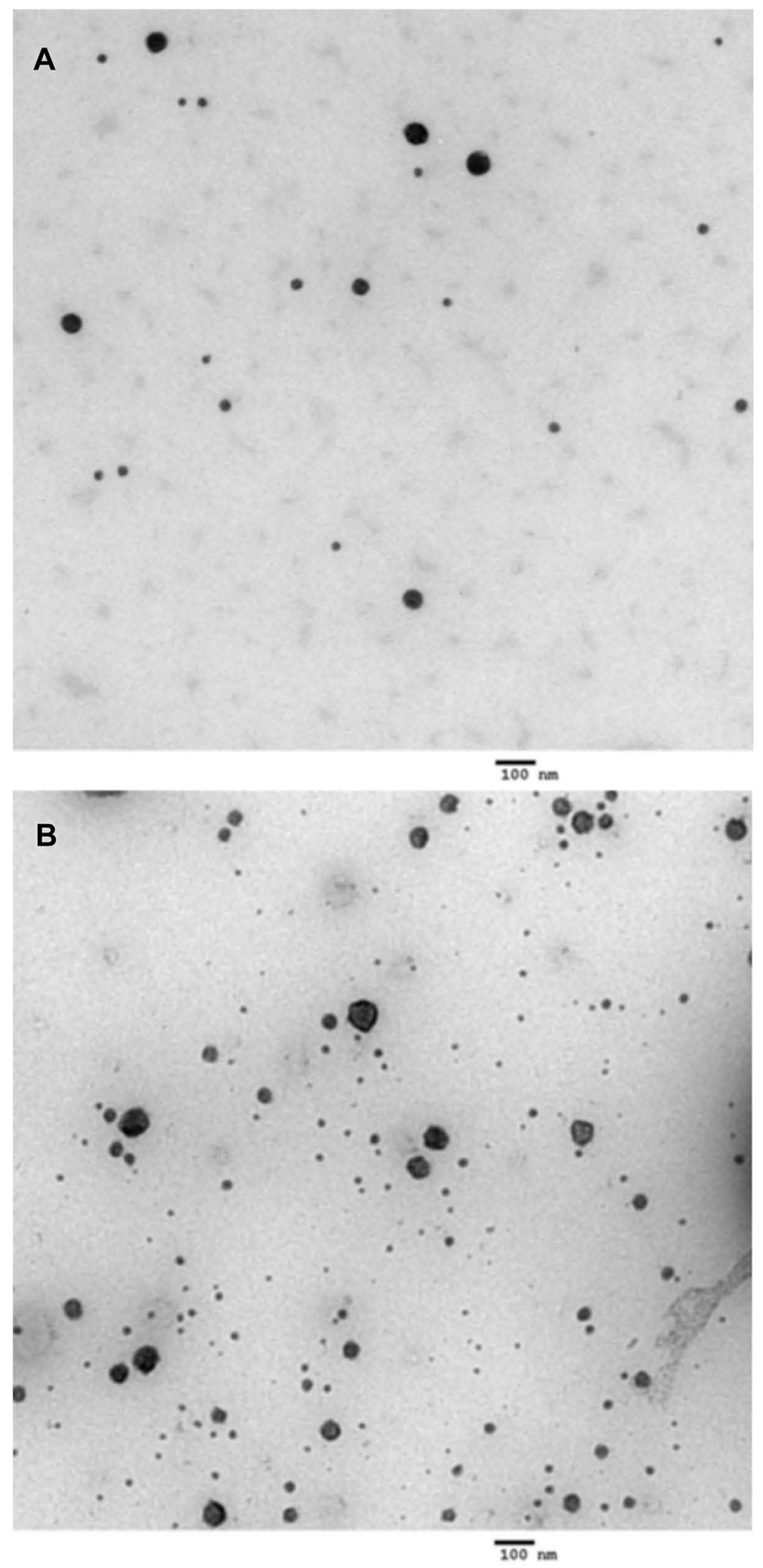

Figure 2 TEM images of the control liposomes $(\mathbf{A})$ and the penetratin-conjugated liposomes (B). 


$$
K_{p}=\frac{J_{s}}{C_{d}}\left(c m \cdot h^{-1}\right)
$$

where $J_{s}$ is the flux $\left(\mathrm{ng} \cdot \mathrm{cm}^{-2} \cdot \mathrm{h}^{-1}\right)$ and $\mathrm{C}_{\mathrm{d}}$ is the initial concentration in the donor chamber $\left(\mathrm{ng} \cdot \mathrm{cm}^{-3}\right)$. Finally, the enhancement ratio (ER) was obtained by dividing the $K_{p}$ value of each formulation with that of the control.

\section{Confocal Laser Scanning Microscopy Imaging Study of Buccal Tissues}

CLSM was used to observe the penetration profile of sCT through buccal tissues optically. Approximately $40 \mu \mathrm{g} / \mathrm{mL}$ Alexa 647-sCT and $1 \mathrm{~mL}$ each of the control liposomes encapsulating Alexa 647-sCT and penetratin-conjugated liposomes were added to the donor chambers of the Franz diffusion cells and were treated for $8 \mathrm{~h}$. After $8 \mathrm{~h}$, the buccal tissues were separated from the Franz diffusion cells. The isolated tissues were then frozen in OCT compound. After freezing, the tissues were cut into $12-\mu \mathrm{m}$ segments using a cryostat microtome and fixed on slides. The Alexa 647 -sCTpermeated tissues were then observed using CLSM.

\section{Statistical Analysis}

Statistical analysis was performed using Student's $t$-test. Data are presented as means \pm standard deviations (SDs). A single, double, or triple asterisk was used for all the data if the p-values were less than $0.05,0.01$, or 0.001 , respectively.

\section{Results}

\section{Physical Characterization of Liposome Formulations}

Table 1 shows the physical characteristics of the control liposomes and the penetratin-conjugated liposomes. The particle size of the two liposomes was approximately $120 \mathrm{~nm}$, which was also shown in the TEM images in Figure 2. The zeta potentials of the control liposomes and penetratin-conjugated liposomes were $-15.7 \mathrm{mV}$ and $+29.6 \mathrm{mV}$, respectively. The encapsulation efficiencies were $27.1 \%$ and $18.0 \%$ for the control liposomes and the penetratin-conjugated liposomes, respectively.

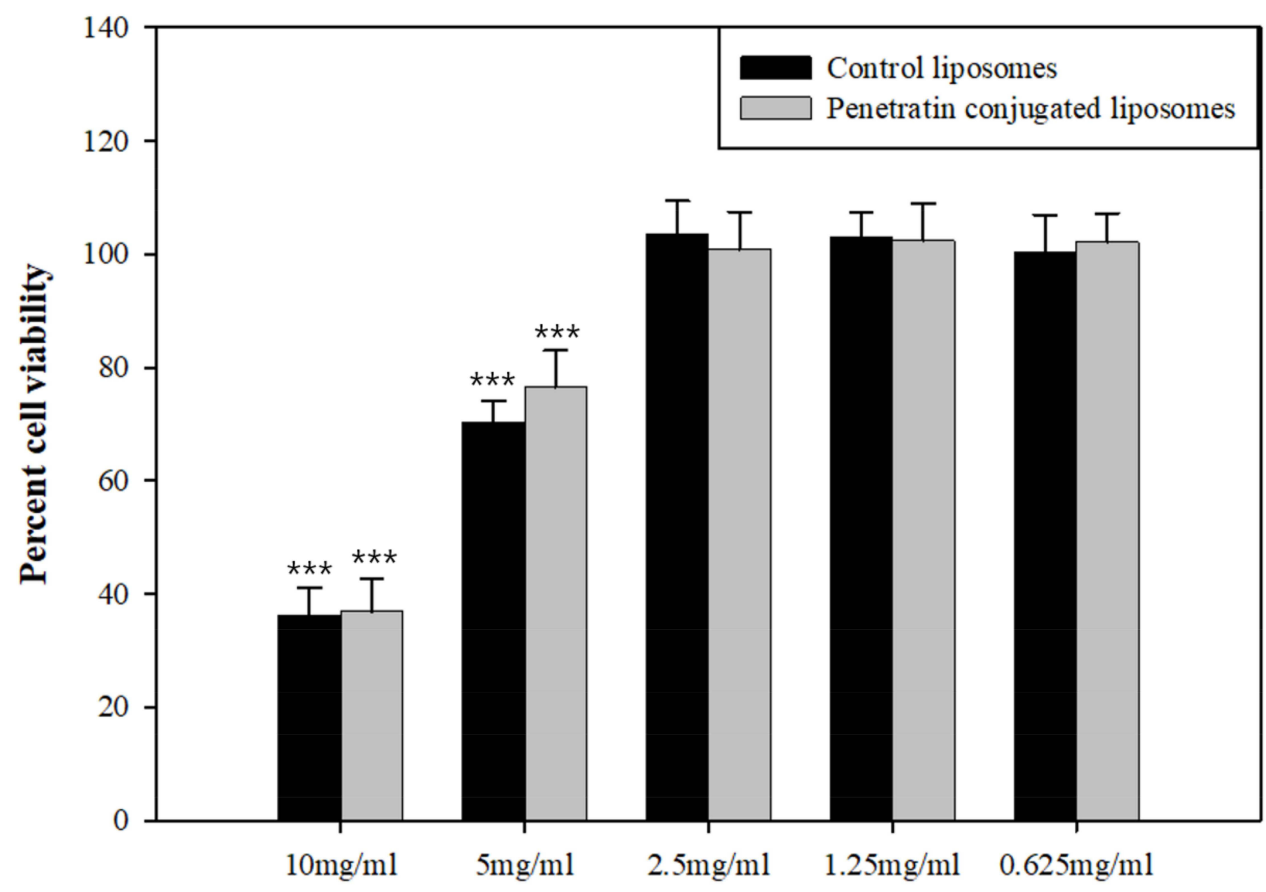

\section{Lipid concentration of liposomes}

Figure 3 Cytotoxicity of various liposome concentrations in TRI46 cells after 24 hours of incubation. Error bars represent $S D(n=5)$. **** $<0.001$ versus control (no treated group). 


\section{Cytotoxicity Assay}

Cytotoxicity was determined by treating TR146 cells with various concentrations of liposomes (Figure 3). The cytotoxicity of each liposome was compared with control (no treated group). The control liposomes and penetratinconjugated liposomes did not show cytotoxicity at concentrations below $2.5 \mathrm{mg} / \mathrm{mL}$. However, as the liposome concentration increased, cytotoxicity also increased, and both liposomes showed cytotoxicity at concentrations of 10 and $5 \mathrm{mg} / \mathrm{mL}$. Since the liposomes were not cytotoxic at $2.5 \mathrm{mg} / \mathrm{mL}$, this concentration was used in the permeation and cell uptake studies.

\section{In vitro Cell Uptake Study}

The cellular uptake efficiency of the liposomes was investigated using relative mean fluorescence intensity and CLSM. Compared to the control liposomes, the fluorescence intensity of Alexa 647-sCT was higher in the penetratin-conjugated liposome-treated group (Figure 4). In the CLSM experiment, the intracellular uptake of Alexa 647-sCT was also higher in the cells treated with penetratin-conjugated liposomes (Figure 5).

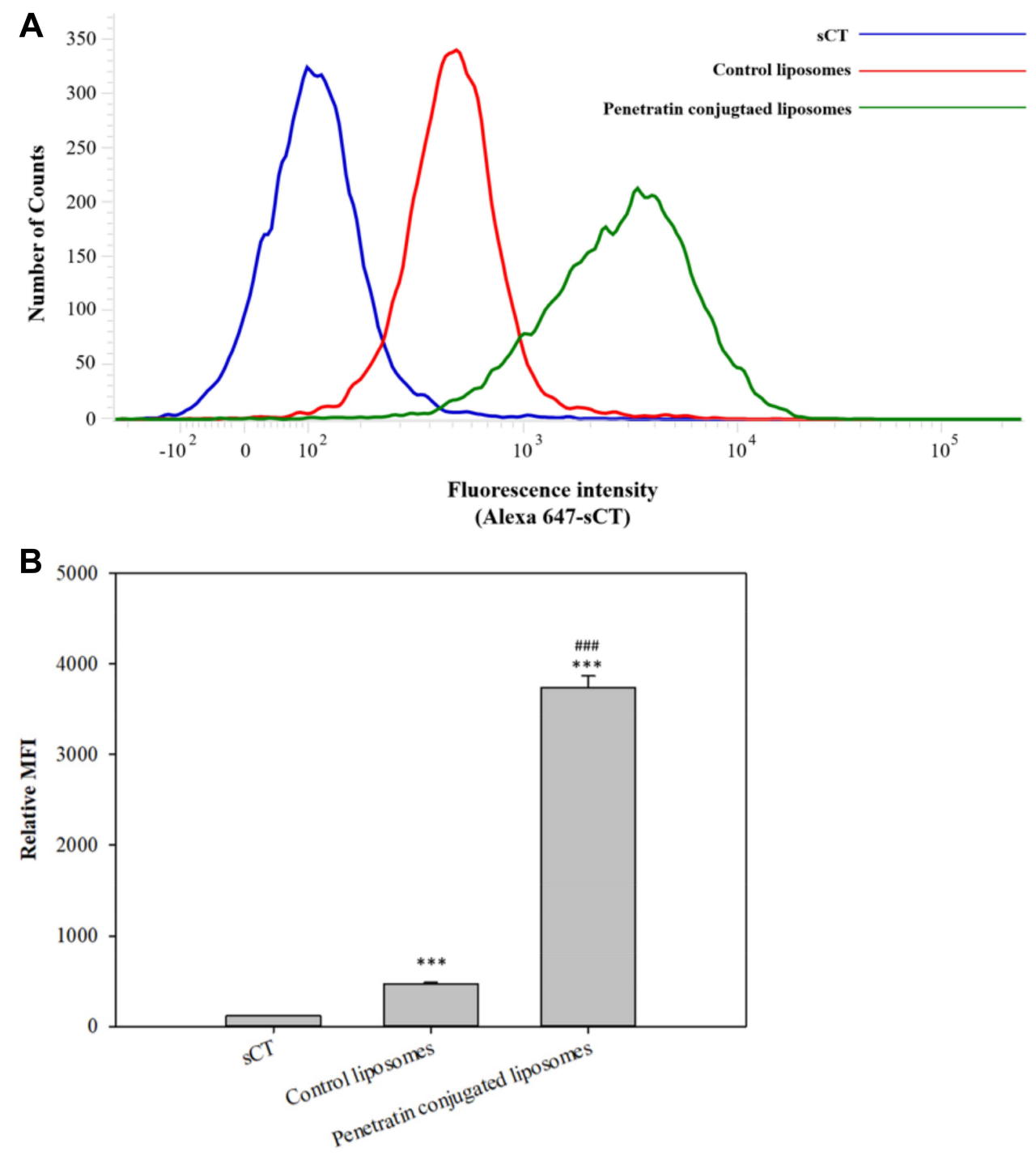

Figure 4 Fluorescence intensities of Alexa 647-sCT after two hours of treatment with the control and penetratin-conjugated liposomes as determined using flow cytometry. Representative fluorescence intensity $(\mathbf{A})$ and relative MFI values of Alexa 647 -sCT (B). All data represent the mean \pm SD $(n=3)$. ${ }^{* * *} \mathrm{p}<0.00 \mathrm{I}$ vs $\mathrm{sCT}$, ${ }^{\# \#} \mathrm{p}<0.00 \mathrm{I}$ vs Control liposomes. 


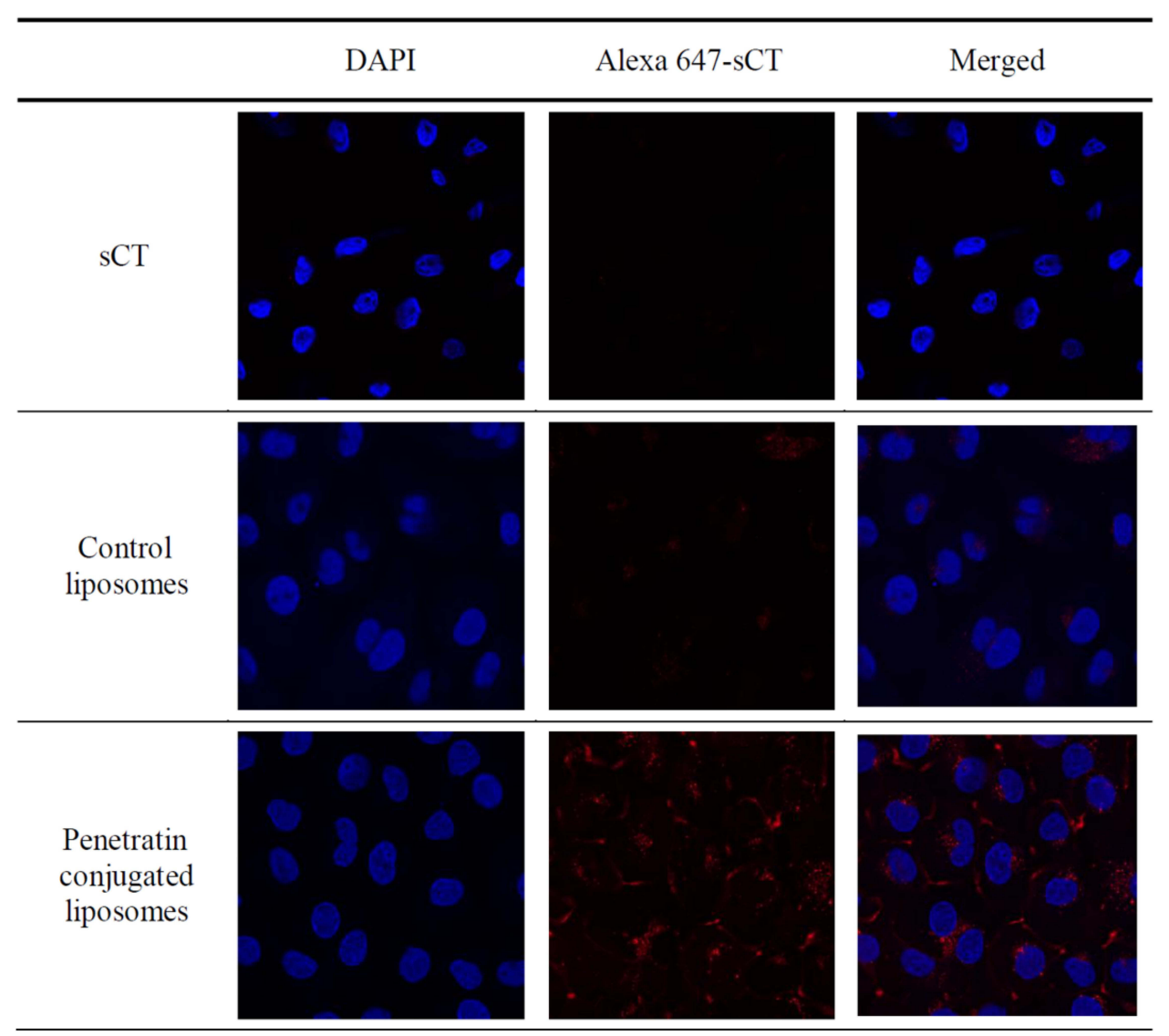

Figure 5 Confocal laser scanning microscopy (CLSM) images of the control liposomes containing Alexa 647-sCT and penetratin-conjugated liposomes in TRI46 cells.

\section{In vitro TRI46 Cell Permeation Study}

TEER is a parameter that determines cell layer integrity. In this study, the maximum TEER value of the TR 146 cell layer cultured for 28 days was $69.07 \Omega \cdot \mathrm{cm}^{2}$. In all the experimental groups, TEER recovery was $>90 \%$. As shown in Table 2 , there was no significant change in TEER values before and after the experiment. In the cell permeation study, the amount of sCT penetrating the cells from the penetratin-conjugated liposomes was 1.93 times higher compared to the control liposomes and 5.8 times higher than that of the free sCT solution (Figure 6 and Table 3).

\section{Ex vivo Buccal Tissue Permeation Study}

A permeation study was conducted using porcine buccal tissue to investigate the permeation-enhancing effect of penetratin-conjugated liposomes. Each liposome group was used to treat buccal tissues for $8 \mathrm{~h}$. The permeation profile at $8 \mathrm{~h}$ of the different liposomes is shown in Figure 7. The $J_{s}$ of sCT solution, control liposomes, and penetratin-

Table 2 TEER Values of the Formulations Before and After Permeability Experiments Using TR I46 Cell Layers

\begin{tabular}{|l|c|c|c|}
\hline \multirow{2}{*}{ Formulation } & \multicolumn{2}{|c|}{ TEER Value $\left(\boldsymbol{\Omega} \mathbf{~ c m}^{2}\right)$} & \multirow{2}{*}{ Recovery (\%) } \\
\cline { 2 - 4 } & Before & After & \\
\hline SCT & $61.97 \pm 3.81$ & $59.73 \pm 3.81$ & $95.40 \pm 0.81$ \\
\hline Control liposomes & $64.96 \pm 1.40$ & $61.97 \pm 1.40$ & $94.76 \pm 1.57$ \\
\hline Penetratin-conjugated liposomes & $64.59 \pm 3.30$ & $61.23 \pm 3.66$ & $96.37 \pm 0.23$ \\
\hline
\end{tabular}

Note: Data are expressed as mean $\pm S D(n=3)$.

Abbreviation: TEER, Transepithelial electrical resistance. 


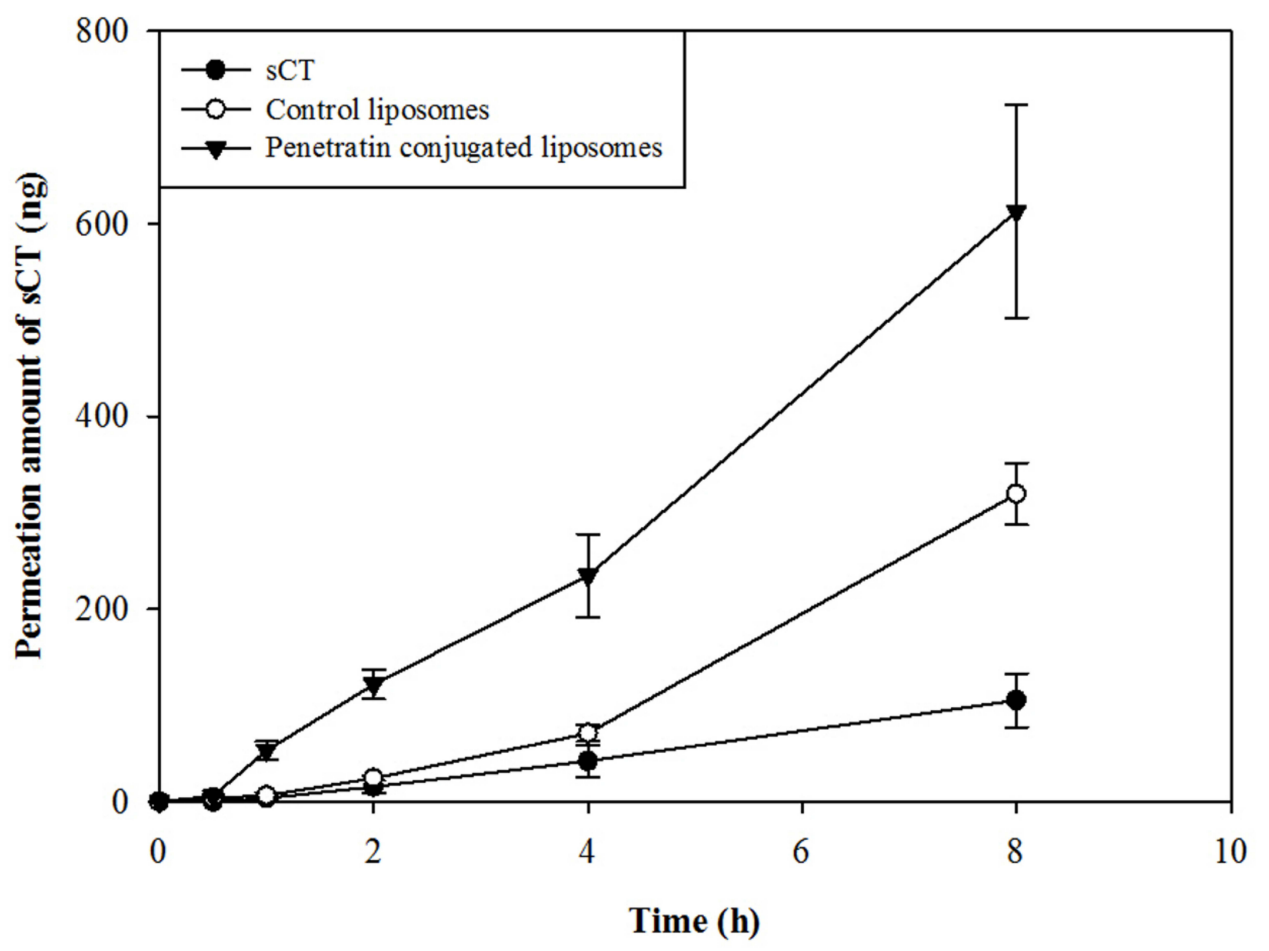

Figure 6 In vitro TRI46 cell permeation profiles of sCT, control liposomes, and penetratin-conjugated liposomes.

conjugated liposomes after $8 \mathrm{~h}$ of permeation were $0.173,6.384$, and $15.802 \mathrm{ng} \cdot \mathrm{cm}^{-2} \cdot \mathrm{h}^{-1}$, respectively. In the penetratinconjugated liposomes, the amount of $\mathrm{sCT}$ permeated increased 91.5 -fold compared to the free $\mathrm{sCT}$ solution group and 2.47-fold compared to the control liposomes (Table 4).

\section{CLSM of Buccal Tissues}

CLSM was used to confirm the permeation-enhancing effect of the penetratin-conjugated liposomes in the buccal tissues. Liposomes containing Alexa 647-sCT were used to treat buccal tissues, which were observed after $8 \mathrm{~h}$. The strongest fluorescence was observed from the tissues treated with penetratin-conjugated liposomes (Figure 8).

\section{Discussion}

CPPs have been widely applied to various cargo molecules in drug delivery systems for several years because of their ability to penetrate cell membranes. CPPs have also been successfully used to deliver biomacromolecules via alternative administration routes. ${ }^{34,35}$ In this study, penetartin-conjugated liposomes encapsulating $\mathrm{sCT}$ were prepared, and their effects in TR146 cells and buccal tissues were evaluated.

A maleimide-thiol reaction was used to prepare the penetratin-conjugated liposomes. The zeta potentials of the control liposomes and the penetratin-conjugated liposomes were $-15.7 \mathrm{mV}$ and $+29.6 \mathrm{mV}$, respectively. This change was

Table 3 Permeation Parameters Calculated from the TRI46 Cell Permeation Study

\begin{tabular}{|l|c|c|c|}
\hline Formulation & $J_{s}\left(\mathbf{n g ~} \mathbf{~ m}^{-2} \mathbf{h}^{-1}\right)$ & $\boldsymbol{K}_{p}\left(\mathbf{c m ~ h}^{-1}\right) \times 10^{-3}$ & ER \\
\hline $\mathrm{sCT}$ & $11.726 \pm 2.527$ & $0.147 \pm 0.032$ & 1.0 \\
\hline Control liposomes & $35.649 \pm 2.906$ & $0.446 \pm 0.036 * * *$ & 3.0 \\
\hline Penetratin-conjugated liposomes & $68.416 \pm 10.093$ & $0.855 \pm 0.126^{* * * *}$ & 5.8 \\
\hline
\end{tabular}

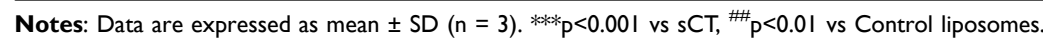

Abbreviations: $J_{s}$, Flux; $K_{p}$, Permeability coefficient; ER, Enhancement ratio. 


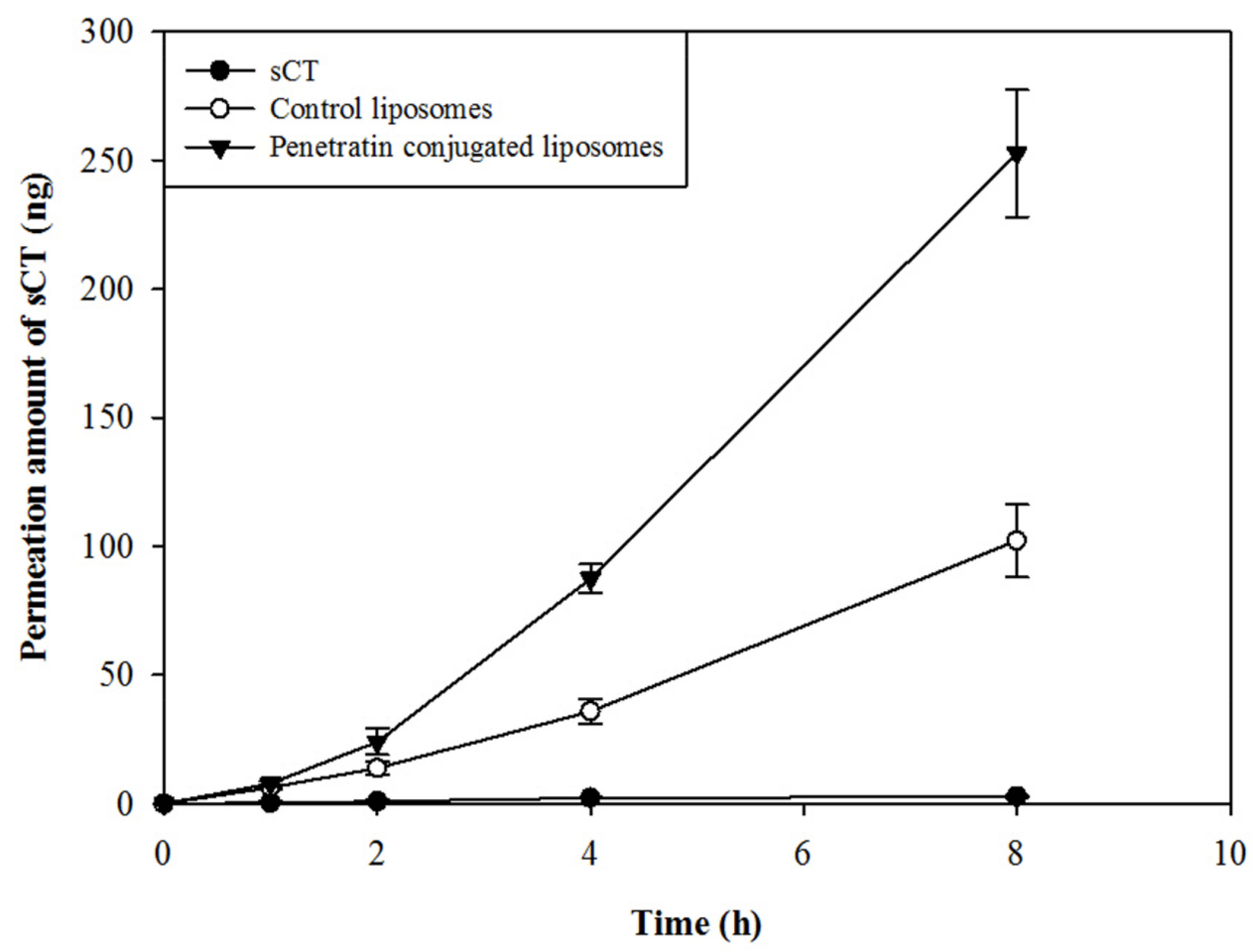

Figure 7 Ex vivo buccal tissue permeation profiles of sCT, control liposomes, and penetratin-conjugated liposomes.

due to the presence of arginine and lysine residues, which are cationic amino acids present in penetratin, suggesting that penetratin was successfully conjugated to the surface of MPB-PE liposomes. ${ }^{30}$ The size of the penetratin-conjugated liposomes was $123.0 \mathrm{~nm}$, with a PDI value of 0.151. The PDI value determines size homogeneity, which suggests that the prepared liposomes have good homogeneity. In lipid-based carriers such as liposomes, PDI values lower than 0.3 indicate homogeneous vesicle distribution. ${ }^{36,37}$

Figure 2 shows the cytotoxicity of the penetratin-conjugated liposomes at various lipid concentrations. Both liposomes showed no cytotoxicity at concentrations below $2.5 \mathrm{mg} / \mathrm{mL}$ but showed cytotoxicity above $5.0 \mathrm{mg} / \mathrm{mL}$. Similar cytotoxicity results observed for the two liposomes indicated that the binding of penetratin did not affect liposome cytotoxicity.

Compared to the control liposomes, the fluorescence intensity of Alexa 647-sCT was higher in the penetratinconjugated liposome-treated tissue. The increased fluorescence intensity of Alexa 647-sCT in the tissues treated with penetratin-conjugated liposomes was due to penetratin binding onto the liposome surface. The arginine residues in penetratin bind to negatively charged components on the cell membrane. ${ }^{38,39}$ Specifically, the guanidinium moieties of arginine bind to the sulfate and carboxylate moieties in GAGs and the phosphates of the phospholipid head group of the membrane lipids while the hydrophobic residue tryptophan is known as an important amino acid for

Table 4 Permeation Parameters Calculated from the Buccal Tissue Permeation Study

\begin{tabular}{|l|c|c|c|}
\hline Formulation & $J_{s}\left(\mathrm{ng} \mathrm{cm}^{-\mathbf{2}} \mathbf{h}^{-1}\right)$ & $K_{p}\left(\mathrm{~cm} \mathrm{~h}^{-1}\right) \times 10^{-3}$ & ER \\
\hline $\mathrm{sCT}$ & $0.173 \pm 0.018$ & $0.004 \pm 0.000$ & 1.0 \\
\hline Control liposomes & $6.384 \pm 0.718$ & $0.160 \pm 0.018 * * *$ & 37.0 \\
\hline Penetratin-conjugated liposomes & $15.802 \pm 1.263$ & $0.395 \pm 0.032 * * * \ldots 1$ & 91.5 \\
\hline
\end{tabular}

Notes: Data are expressed as mean $\pm \mathrm{SD}(\mathrm{n}=3) .{ }^{* * *} \mathrm{p}<0.00 \mathrm{I}$ vs $\mathrm{sCT},{ }^{\# \#} \mathrm{p}<0.00 \mathrm{I}$ vs Control liposomes.

Abbreviations: $J_{s}$, Flux; $K_{p}$, Permeability coeficient; ER, Enhancement ratio. 


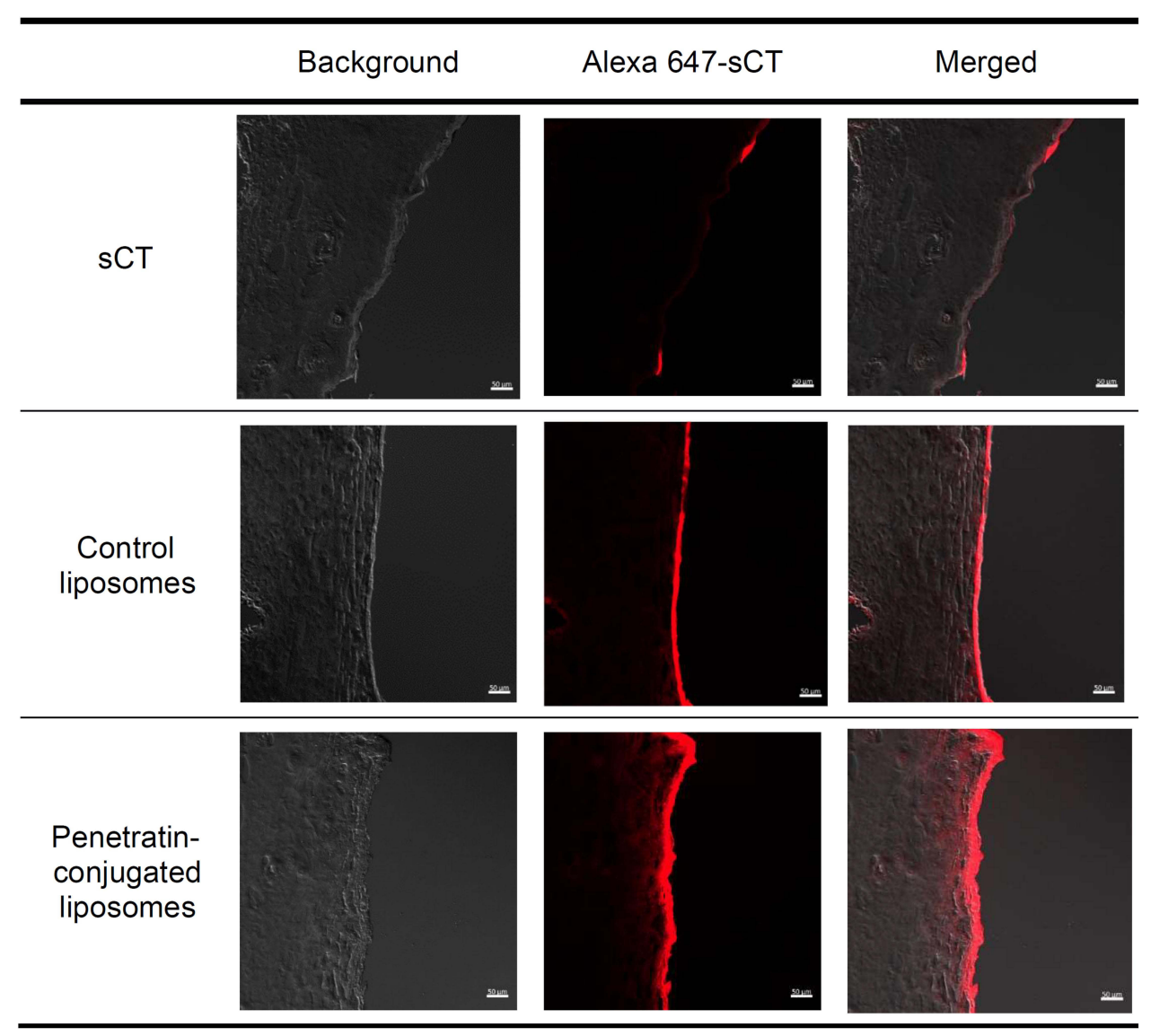

Figure 8 Confocal laser scanning microscopy (CLSM) images of the control liposomes containing Alexa 647-sCT and the penetratin-conjugated liposomes after permeation through the buccal tissue at $8 \mathrm{~h}$.

internalization into cells. ${ }^{38,40,41}$ In addition, tryptophan is also known to induce lipid bilayers to form negative curvatures. $^{42}$

The TEER value indicates the integrity of the cell layers and tight junctions. ${ }^{43}$ The recovery of the TEER values before and after the liposome formulation experiment was more than $90 \%$ without any significant decrease. Penetratin did not affect the TEER value of TR 146 cell layers. Similarly, treatment with penetratin-conjugated liposomes did not affect the TEER value, suggesting that it does not change the integrity of the cell layers and the tight junctions. ${ }^{21,43}$ The amount of SCT that penetrated the TR 146 cell layer was higher in the penetratin-conjugated liposomes than in the control liposomes, which indicates that penetratin conjugated to the liposomes enhanced cell permeation. Penetratin acted as a permeation enhancer in the Buccal pathway and effectively enhanced the permeation of sCT when physically mixed with $\mathrm{sCT} .{ }^{29}$ Penetratin-conjugated liposomes also increased the amount of SCT permeation. This means that penetratin acts as an effective permeation enhancer in the physical mixture and conjugating to the liposome. The FACS and CLSM results supported that penetratin-conjugated liposomes enhanced permeation through transcellular routes. Likewise, penetratin-conjugated liposomes also had increased cell permeability compared to control liposomes in the porcine tissue permeation study (Figures 6 and 7). Results of the permeation experiments in TR 146 cells and porcine buccal tissues showed that penetratin-conjugated liposomes could enhance the permeation of $\mathrm{SCT}$ in cell layers and tissues. CLSM results revealed that penetratin-conjugated liposomes showed an increase in fluorescence intensity compared to control liposomes.

\section{Conclusions}

We designed penetratin-conjugated liposomes to deliver sCT through the buccal tissues. Flow cytometry and CLSM studies showed that penetratin-conjugated liposomes had an improved cellular sCT uptake effect. In addition, penetratin- 
conjugated liposomes showed enhanced permeation effect in vitro and ex vivo experiment model. Although further in vivo studies are needed to demonstrate the permeation mechanism of penetratin-conjugated liposomes, these studies fully demonstrate the potential of penetratin-conjugated liposomes as a platform for buccal delivery of peptide drugs.

\section{Funding}

This research was supported by the Basic Science Research Program through the National Research Foundation of Korea (NRF) funded by the Ministry of Sciences, ICT, and Future Planning (NRF-2016R1D1A1B01015369 and NRF2016R1A6A1A03011325).

\section{Disclosure}

The authors report no conflicts of interest in this work.

\section{References}

1. Copp DH, Cameron EC. Demonstration of a hypocalcemic factor (calcitonin) in commercial parathyroid extract. Science. 1961;134(3495):2038. doi:10.1126/science.134.3495.2038.a

2. Chesnut CH 3rd, Azria M, Silverman S, et al. Salmon calcitonin: a review of current and future therapeutic indications. Osteoporos Int. $2008 ; 19$ (4):479-491. doi:10.1007/s00198-007-0490-1

3. Chesnut $\mathrm{CH}$ 3rd, Silverman S, Andriano K, et al. A randomized trial of nasal spray salmon calcitonin in postmenopausal women with established osteoporosis: the prevent recurrence of osteoporotic fractures study. PROOF study group. Am J Med. 2000;109(4):267-276. doi:10.1016/S00029343(00)00490-3

4. Calis S, Jeyanthi R, Tsai T, et al. Adsorption of salmon calcitonin to PLGA microspheres. Pharm Res. 1995;12(7):1072-1076. doi:10.1023/ A:1016278902839

5. Guggi D, Kast CE, Bernkop-Schnürch A. In vivo evaluation of an oral salmon calcitonin-delivery system based on a thiolated chitosan carrier matrix. Pharm Res. 2003;20(12):1989-1994. doi:10.1023/B:PHAM.0000008047.82334.7d

6. Lee HE, Lee MJ, Park CR, et al. Preparation and characterization of salmon calcitonin-sodium triphosphate ionic complex for oral delivery. $J$ Control Release. 2010;143(2):251-257. doi:10.1016/j.jconrel.2009.12.011

7. Junginger HE, Hoogstraate JA, Verhoef JC. Recent advances in buccal drug delivery and absorption-in vitro and in vivo studies. $J$ Control Release. 1999;62(1-2):149-159. doi:10.1016/S0168-3659(99)00032-2

8. Veuillez F, Kalia YN, Jacques Y, et al. Factors and strategies for improving buccal absorption of peptides. Eur J Pharm Biopharm. 2001;51 (2):93-109. doi:10.1016/S0939-6411(00)00144-2

9. Caon T, Jin L, Simões CMO, et al. Enhancing the buccal mucosal delivery of peptide and protein therapeutics. Pharm Res. 2015;32(1):1-21. doi:10.1007/s11095-014-1485-1

10. Senel S, Kremer M, Katalin N, et al. Delivery of bioactive peptides and proteins across oral (buccal) mucosa. Curr Pharm Biotechnol. 2001;2 (2):175-186. doi:10.2174/1389201013378734

11. Salamat-Miller N, Chittchang M, Johnston TP. The use of mucoadhesive polymers in buccal drug delivery. Adv Drug Deliv Rev. 2005;57 (11):1666-1691. doi:10.1016/j.addr.2005.07.003

12. Okafor NI, Nkanga CI, Walker RB, et al. Encapsulation and physicochemical evaluation of efavirenz in liposomes. J Pharm Investig. 2020;50 (2):201-208. doi:10.1007/s40005-019-00458-8

13. Akbarzadeh A, Rezaei-Sadabady R, Davaran S, et al. Liposome: classification, preparation, and applications. Nanoscale Res Lett. $2013 ; 8(1): 102$. doi:10.1186/1556-276X-8-102

14. Kiio TM, Park S. Physical properties of nanoparticles do matter. J Pharm Investig. 2021;51(1):35-51. doi:10.1007/s40005-020-00504-w

15. Zeb A, Cha J-H, Noh AR, et al. Neuroprotective effects of carnosine-loaded elastic liposomes in cerebral ischemia rat model. J Pharm Investig. 2020;50(4):373-381. doi:10.1007/s40005-019-00462-y

16. Abd El Azim H, Nafee N, Ramadan A, et al. Liposomal buccal mucoadhesive film for improved delivery and permeation of water-soluble vitamins. Int J Pharm. 2015;488(1-2):78-85. doi:10.1016/j.ijpharm.2015.04.052

17. Torchilin VP. Recent advances with liposomes as pharmaceutical carriers. Nat Rev Drug Discov. 2005;4(2):145-160. doi:10.1038/nrd1632

18. Yang TZ, Wang X-T, Yan X-Y, et al. Phospholipid deformable vesicles for buccal delivery of insulin. Chem Pharm Bull. 2002;50(6):749-753. doi:10.1248/cpb.50.749

19. El-Samaligy MS, Afifi NN, Mahmoud EA. Increasing bioavailability of silymarin using a buccal liposomal delivery system: preparation and experimental design investigation. Int J Pharm. 2006;308(1-2):140-148. doi:10.1016/j.ijpharm.2005.11.006

20. Lankalapalli S, Tenneti VS. Formulation and evaluation of rifampicin liposomes for buccal drug delivery. Curr Drug Deliv. 2016;13(7):1084-1099. doi:10.2174/1567201813666151221145617

21. Bashyal S, Seo J-E, Keum T, et al. Facilitated permeation of insulin across TR146 cells by cholic acid derivatives-modified elastic bilosomes. Int J Nanomed. 2018;13:5173-5186. doi:10.2147/IJN.S168310

22. Bashyal S, Seo J-E, Keum T, et al. Development, characterization, and ex vivo assessment of elastic liposomes for enhancing the buccal delivery of insulin. Pharmaceutics. 2021;13(4):565. doi:10.3390/pharmaceutics13040565

23. Kurrikoff K, Gestin M, Langel Ü. Recent in vivo advances in cell-penetrating peptide-assisted drug delivery. Expert Opin Drug Deliv. 2016;13 (3):373-387. doi:10.1517/17425247.2016.1125879

24. Langel Ü. Handbook of Cell-Penetrating Peptides. CRC press; 2006.

25. Kim CH, Lee SG, Kang MJ, et al. Surface modification of lipid-based nanocarriers for cancer cell-specific drug targeting. J Pharm Investig. 2017;47(3):203-227. doi:10.1007/s40005-017-0329-5 
26. Wang F, Wang Y, Zhang X, et al. Recent progress of cell-penetrating peptides as new carriers for intracellular cargo delivery. $J$ Control Release. 2014;174:126-136. doi:10.1016/j.jconrel.2013.11.020

27. Gao H, Zhang Q, Yu Z, et al. Cell-penetrating peptide-based intelligent liposomal systems for enhanced drug delivery. Curr Pharm Biotechnol. 2014;15(3):210-219. doi:10.2174/1389201015666140617092552

28. Xu Y, Zhang X, Wang N, et al. Cell-penetrating peptide enhanced insulin buccal absorption. Int J Pharm. 2020;584:119469. doi:10.1016/j. ijpharm.2020.119469

29. Keum T, Noh G, Seo J-E, et al. In vitro and ex vivo evaluation of penetratin as a non-invasive permeation enhancer in the penetration of salmon calcitonin through TR146 buccal cells and porcine buccal tissues. Pharmaceuticals. 2020;13(11):408. doi:10.3390/ph13110408

30. Kwon SS, Kim SY, Kong BJ, et al. Cell penetrating peptide conjugated liposomes as transdermal delivery system of Polygonum aviculare L. extract. Int J Pharm. 2015;483(1-2):26-37. doi:10.1016/j.ijpharm.2015.01.030

31. Yang Y, Yang Y, Xie X, et al. PEGylated liposomes with NGR ligand and heat-activable cell-penetrating peptide-doxorubicin conjugate for tumor-specific therapy. Biomaterials. 2014;35(14):4368-4381. doi:10.1016/j.biomaterials.2014.01.076

32. Nielsen HM, Verhoef JC, Ponec M, et al. TR146 cells grown on filters as a model of human buccal epithelium: permeability of fluorescein isothiocyanate-labelled dextrans in the presence of sodium glycocholate. J Control Release. 1999;60(2-3):223-233. doi:10.1016/S0168-3659(99) 00081-4

33. Oh DH, Chun K-H, Jeon S-O, et al. Enhanced transbuccal salmon calcitonin (sCT) delivery: effect of chemical enhancers and electrical assistance on in vitro sCT buccal permeation. Eur J Pharm Biopharm. 2011;79(2):357-363. doi:10.1016/j.ejpb.2011.05.010

34. Dietz GP, Bähr M. Delivery of bioactive molecules into the cell: the Trojan horse approach. Mol Cell Neurosci. 2004;27(2):85-131. doi:10.1016/j. men.2004.03.005

35. Tang J, Zhang L, Fu H, et al. A detachable coating of cholesterol-anchored PEG improves tumor targeting of cell-penetrating peptide-modified liposomes. Acta Pharm Sin B. 2014;4(1):67-73. doi:10.1016/j.apsb.2013.12.004

36. Chen M, Liu X, Fahr A. Skin penetration and deposition of carboxyfluorescein and temoporfin from different lipid vesicular systems: in vitro study with finite and infinite dosage application. Int J Pharm. 2011;408(1-2):223-234. doi:10.1016/j.ijpharm.2011.02.006

37. Danaei M, Dehghankhold M, Ataei S, et al. Impact of particle size and polydispersity index on the clinical applications of lipidic nanocarrier systems. Pharmaceutics. 2018;10(2):57. doi:10.3390/pharmaceutics10020057

38. Rothbard JB, Jessop TC, Lewis RS, et al. Role of membrane potential and hydrogen bonding in the mechanism of translocation of guanidinium-rich peptides into cells. $J$ Am Chem Soc. 2004;126(31):9506-9507. doi:10.1021/ja0482536

39. Walrant A, Bauzá A, Girardet C, et al. Ionpair- $\pi$ interactions favor cell penetration of arginine/tryptophan-rich cell-penetrating peptides. Biochim Biophys Acta Biomembr. 2020;1862(2):183098. doi:10.1016/j.bbamem.2019.183098

40. Rothbard JB, Jessop TC, Wender PA. Adaptive translocation: the role of hydrogen bonding and membrane potential in the uptake of guanidinium-rich transporters into cells. Adv Drug Deliv Rev. 2005;57(4):495-504. doi:10.1016/j.addr.2004.10.003

41. Sakai N, Matile S. Anion-mediated transfer of polyarginine across liquid and bilayer membranes. J Am Chem Soc. 2003;125(47):14348-14356. doi:10.1021/ja0376011

42. Berlose JP, Convert O, Derossi D, et al. Conformational and associative behaviours of the third helix of antennapedia homeodomain in membrane-mimetic environments. Eur J Biochem. 1996;242(2):372-386. doi:10.1111/j.1432-1033.1996.0372r.x

43. Srinivasan B, Kolli AR, Esch MB, et al. TEER measurement techniques for in vitro barrier model systems. J Lab Autom. 2015;20(2):107-126. doi: $10.1177 / 2211068214561025$

International Journal of Nanomedicine

\section{Publish your work in this journal}

The International Journal of Nanomedicine is an international, peer-reviewed journal focusing on the application of nanotechnology in diagnostics, therapeutics, and drug delivery systems throughout the biomedical field. This journal is indexed on PubMed Central, MedLine, CAS, SciSearch ${ }^{\circledR}$, Current Contents ${ }^{\mathbb{B}} /$ Clinical Medicine, Journal Citation Reports/Science Edition, EMBase, Scopus and the Elsevier Bibliographic databases. The manuscript management system is completely online and includes a very quick and fair peer-review system, which is all easy to use. Visit http:// www.dovepress.com/testimonials.php to read real quotes from published authors.

Submit your manuscript here: https://www.dovepress.com/international-journal-of-nanomedicine-journal 